\title{
MONITORAMENTO DA FRENTE DE COMBUSTÃO DAS VENTANEIRAS DO ALTO-FORNO 3 DA USIMINAS - USINA DE IPATINGA*
}

\author{
Luiz Carlos Teixeira Brandão ${ }^{1}$ \\ Sabrina Magalhães Macedo² \\ Marco Aurélio Garcia de Oliveira ${ }^{3}$
}

\begin{abstract}
Resumo
O Alto-Forno 3 da Usiminas em Ipatinga, que atualmente está na sua quarta campanha, apresenta 30 ventaneiras. Nesta campanha houve alguns eventos de arrombamento e avermelhamento dos algaravizes. A causa destas ocorrências são obstruções das frentes de combustão das ventaneiras, gerando diversos transtornos operacionais. A fim de se evitar novos fatos semelhantes foram desenvolvidos alguns sistemas de monitoramento das frentes de combustão. Dentre os sistemas desenvolvidos se destacam o diferencial de pressão do conjunto de sopro; e, o controle da temperatura do conjunto de sopro. Os sistemas desenvolvidos permitiram maior confiabilidade nas ações imediatas dos operadores em anormalidades na zona de combustão com consequente ganho em desempenho operacional do alto-forno.
\end{abstract}

Palavras-chave: Diferencial de pressão; Algaraviz; Ventaneira; Temperatura.

\section{MONITORING THE FRONT OF COMBUSTION TUYERES AT USIMINAS'S BLAST FURNACE\#3 - IPATINGA PLANT}

\begin{abstract}
Usiminas Blast Furnace\#3, in Ipatinga, which is in its fourth campaign, has 30 tuyeres. Recently it has been observed some hot spots and breaks in its blow pipes. The reasons for this problem are blocks in the tuyeres front and this situation causes several operational problems. Because of this, some monitoring systems of raceway it were developed, such as blow pipes differential pressure; and, blow pipes temperature control and raceway monitoring. The systems developed allow more reliability on immediate actions of specialist regarding raceway abnormalities with consequent better blast furnace performance.
\end{abstract}

Keywords: Blast furnace; Differential pressure; Blow pipes; Tuyeres; Temperature.

1 Técnico Metalurgista, Gerência de Alto-Forno 3; Usiminas, Ipatinga, MG, Brasil.

2 Engenheira Eletricista, Gerência de Manutenção de Sistemas Industriais; Usiminas, Ipatinga, MG, Brasil.

3 Engenheiro Metalurgista, Gerência Técnica de Redução; Usiminas, Ipatinga, MG, Brasil.

\footnotetext{
* Contribuição técnica ao $44^{\circ}$ Seminário de Redução de Minério de Ferro e Matérias-primas, $15^{\circ}$ Simpósio Brasileiro de Minério de Ferro e $2^{\circ}$ Simpósio Brasileiro de Aglomeração de Minério de Ferro, 15 a 18 de setembro de 2014, Belo Horizonte, MG, Brasil.
} 


\section{INTRODUÇÃO}

Os altos-fornos são reatores utilizados para a produção de ferro gusa. As principais matérias-primas carregadas, pelo topo do alto-forno, são o sínter, minério de ferro granulado, pelota e o principal combustível utilizado é o coque metalúrgico.

Na região inferior é injetado ar quente e oxigênio que, ao reagir com o coque e com o carvão injetado pelas ventaneiras, gera o gás redutor monóxido de carbono (CO) e grande quantidade de calor. O gás de alto-forno flui em direção ao topo, em sentido contrário à descida da carga, proporcionando o aquecimento, a redução e a fusão da carga metálica. Como produtos desta redução, são gerados o ferro gusa e a escória [1].

A Usina de Ipatinga possui três altos-fornos, sendo os Altos-Fornos 1 e 2, com volume interno de $885 \mathrm{~m}^{3}$ cada um, e o Alto-Forno 3, que responde por cerca de $70 \%$ da produção de gusa, cujas principais características são apresentadas na tabela 1.

Recentemente, houve alguns eventos de arrombamento e avermelhamento do conjunto de sopro no Alto-Forno 3. Considerando os impactos destas ocorrências, percebeu-se a necessidade de implantar o sistema de monitoramento da frente de combustão das ventaneiras e do conjunto de sopro propriamente dito, tendo como foco principal a redução do custo e principalmente a segurança operacional.

Tabela 1. Principais características do Alto-Forno 3 da Usiminas Ipatinga

\begin{tabular}{l|l|l}
\hline Itens & Unidade & $\mathrm{AF3}$ \\
\hline Volume interno & $\mathrm{m}^{3}$ & 3163 \\
\hline Volume de trabalho & $\mathrm{m}^{3}$ & 2950 \\
\hline Diâmetro do cadinho & $\mathrm{m}$ & 12,2 \\
\hline Capacidade de produção & $\mathrm{t} / \mathrm{dia}$ & 8200 \\
\hline Número de ventaneiras & - & 30 \\
\hline Número de furo de gusa & - & 3 \\
\hline Topo & - & Duplo cone \\
\hline Sistema de granulação & - & INBA \\
\hline Temperatura máxima de sopro & $-\mathrm{C}$ & 1200 \\
\hline Sistema de refrigeração cuba, ventre, rampa e cadinho & - & Stave-coolers \\
\hline Início da campanha atual & - & $29 / 10 / 1999$ \\
\hline
\end{tabular}

\section{DESENVOLVIMENTO}

\subsection{Causas e Mecanismos que Provocam o Fenômeno}

Em decorrência de desprendimentos de cargas inativas ou despreparadas da zona seca do forno que se alojam na região frontal das ventaneiras, ocorre obstrução total ou parcial do conjunto de sopro com carvão pulverizado. Neste caso, os combustíveis auxiliares [2] podem retornar através do algaraviz no sentido do anel de vento, e serem carreados para o conjunto joelho/algaraviz adjacente no sentido do fluxo de ar quente no anel de vento. Posteriormente, estes entram em combustão no interior do algaraviz para o qual foram carreados, causando fusão do revestimento refratário e consequentemente avermelhamento e/ou colapso estrutural do conjunto de sopro, conforme ilustrado na figura 1.

\footnotetext{
* Contribuição técnica ao $44^{\circ}$ Seminário de Redução de Minério de Ferro e Matérias-primas, $15^{\circ}$ Simpósio Brasileiro de Minério de Ferro e $2^{\circ}$ Simpósio Brasileiro de Aglomeração de Minério de Ferro, 15 a 18 de setembro de 2014, Belo Horizonte, MG, Brasil.
} 


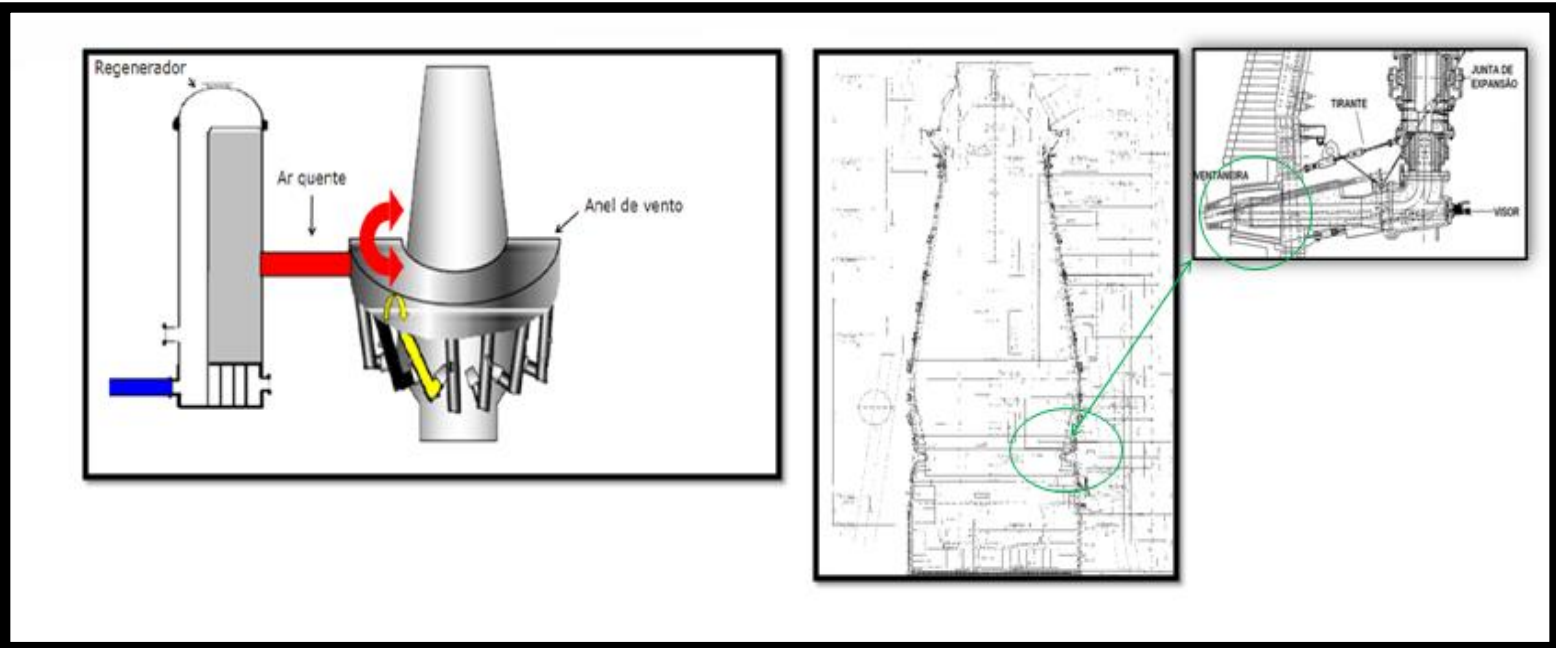

Figura 1. Esquema ilustrativo da ocorrência do fenômeno de obstrução da algaraviz.

Como contramedida para evitar as ocorrências de rompimento de algaravizes no Alto-Forno 3 da usina de Ipatinga, foi implantado a partir do mês de abril de 2013, o controle por variação de temperatura, denominado $\Delta \mathrm{T}$ (diferencial de temperatura) de algaravizes; e, no mês seguinte, o sistema de controle por diferença de pressão, denominado o $\Delta \mathrm{P}$ (diferencial de pressão) de ventaneiras.

Esses sistemas permitem a automatização do monitoramento térmico de algaravizes e de pressão de ventaneiras do alto-forno, melhorando a gestão das ocorrências, possibilitando ao operador uma maior confiabilidade nas tomadas de decisão.

Nesta contribuição técnica é apresentada a configuração destes sistemas bem como os resultados operacionais alcançados pelo Alto-Forno 3 após sua instalação.

\subsection{Sistema de Controle por Diferencial de Pressão do Conjunto de Sopro}

O sistema de diferencial de pressão é controlado por transmissores instalados nos conjuntos de sopro, tomando como referência a diferença de pressão calculada entre o transmissor de pressão de base do alto-forno. É instalado no trecho reto da tubulação de ar quente anterior ao anel de vento e os transmissores individuais de cada conjunto de sopro. Toda informação é enviada e monitorada por estações de supervisório instaladas na sala de controle central, atuando conforme lógica préestabelecida, desligando a injeção de combustíveis auxiliares sempre que uma anormalidade for detectada.

O critério de desarme da injeção de combustíveis auxiliares (gás natural e carvão pulverizado) e ligação simultânea da inertização com nitrogênio é quando a diferença de pressão calculada entre os dois transmissores atingir o set point visado para desarme e permanecer por 10 segundos abaixo deste valor.

Todos os alarmes do sistema, além de exibir informação na barra de alarmes da tela do supervisório de prioridade 1, também serão exibidos na tela como prioridade 3 , conforme figura 2. Ou seja, uma janela pop up deverá alertar o operador, indicando que já foi desligada a injeção de combustíveis da ventaneira em questão e das ventaneiras adjacentes.

\footnotetext{
* Contribuição técnica ao 44 Seminário de Redução de Minério de Ferro e Matérias-primas, $15^{\circ}$ Simpósio Brasileiro de Minério de Ferro e $2^{\circ}$ Simpósio Brasileiro de Aglomeração de Minério de Ferro, 15 a 18 de setembro de 2014, Belo Horizonte, MG, Brasil.
} 


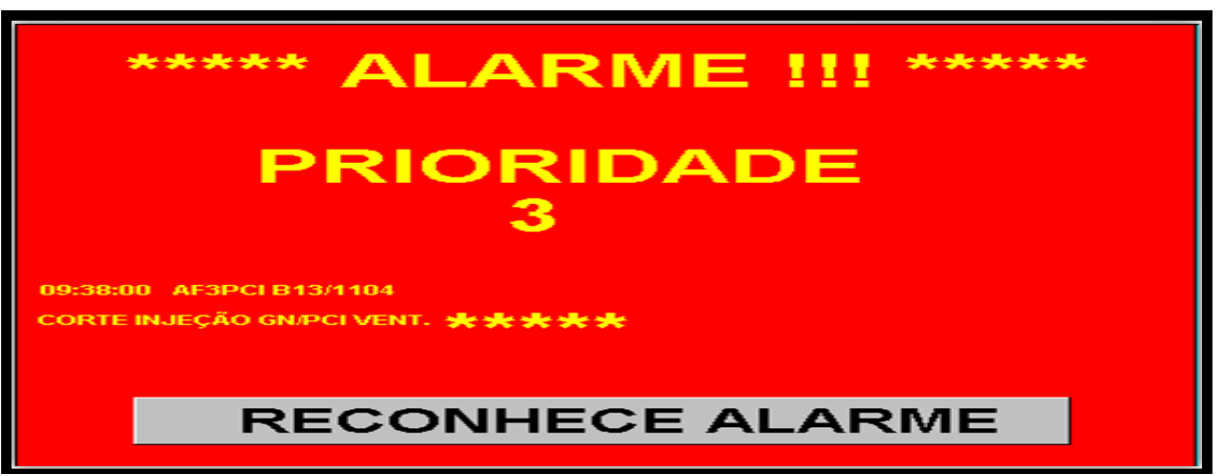

Figura 2. Tela da estação de supervisório informando alarme.

Após o desarme de injeção de carvão pulverizado e gás natural em uma ventaneira pelo sistema descrito, esta é inspecionada, observando a frente de combustão, irregularidades, retorno de escória, cascão parado, obstrução com carvão pulverizado e visor sujo. A retomada da injeção estará condicionada a inspeção criteriosa dos itens citados acima, liberando ou não a injeção naquela ventaneira.

As flutuações, acompanhadas online por gráficos de barra na tela do supervisório (figura 3), podem indicar o comportamento do alto-forno no que diz respeito à permeabilidade na sua base, ou seja, a facilidade com que o ar quente está passando pela ventaneira e penetrando na carga. Desta forma é possível traçar um perfil radial, verificando o balanceamento do alto-forno, bem como atuar caso seja necessário, de maneira a garantir o comportamento mais constante possível das ventaneiras. Esta informação de maneira precisa pode evitar instabilidade operacional no alto-forno, o que causa redução de produção e/ou consumo elevado de combustível. Toda avaliação destes dados é feita por meio da ferramenta gráfica de gestão das informações da planta.

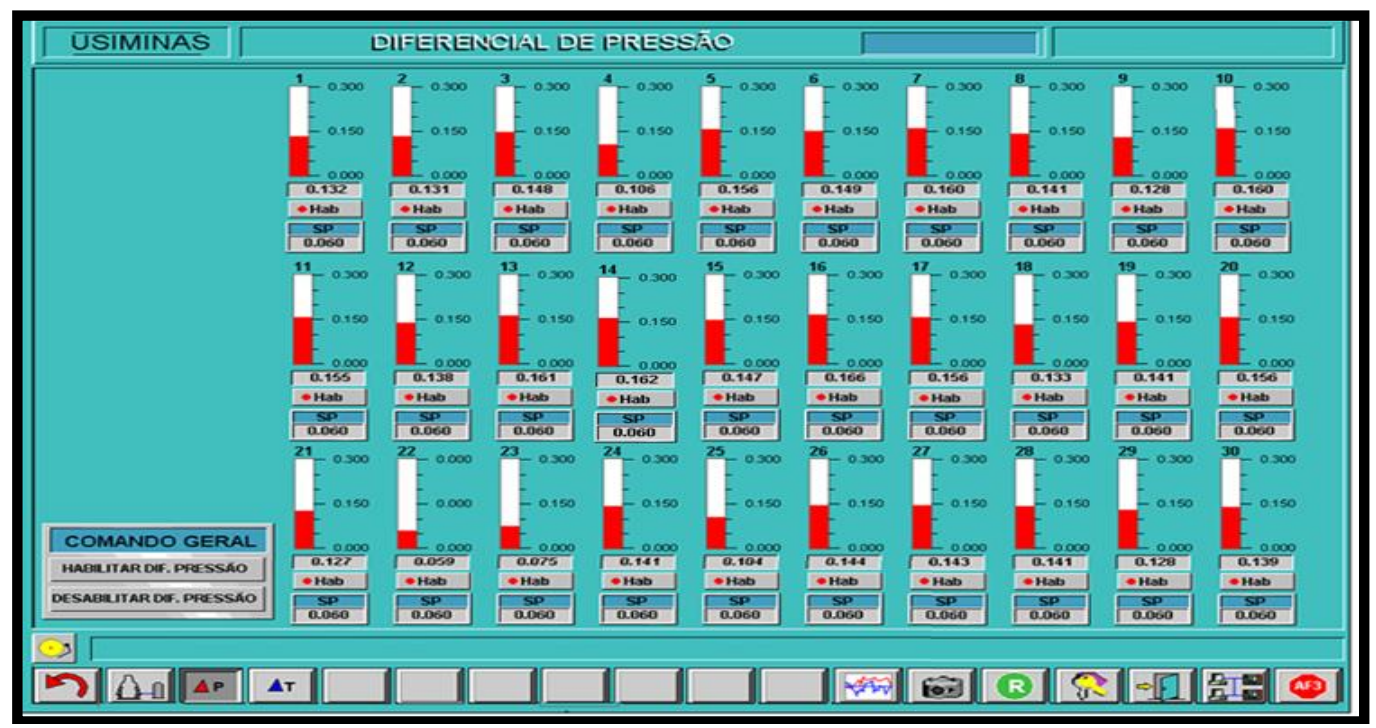

Figura 3. Tela da estação de supervisório do sistema de diferencial de pressão.

\subsection{Sistema de Controle por Diferencial de Temperatura do Conjunto de Sopro}

O sistema de diferencial de temperatura é controlado por termopares de contato, que são fixados na chaparia dos algaravizes. Esses estão instalados aproximadamente a $350 \mathrm{~mm}$ da ponta do algaraviz e $150 \mathrm{~mm}$ deslocado da parte superior para esquerda conforme apresentado na figura 4.

* Contribuição técnica ao 44 Seminário de Redução de Minério de Ferro e Matérias-primas, 15 Simpósio Brasileiro de Minério de Ferro e 2ํ Simpósio Brasileiro de Aglomeração de Minério de Ferro, 15 a 18 de setembro de 2014, Belo Horizonte, MG, Brasil. 
do valor médio de temperatura igual a $230^{\circ} \mathrm{C}$. Isto se justifica em função da elevação natural de temperatura dos algaravizes no reinício de marcha, o que iria confrontar com a lógica de corte por temperatura alta. Um alarme será gerado informando a hora de habilitar o sistema de controle; ou, quando do início da injeção de combustíveis auxiliares. Toda avaliação destes dados é feita por meio da ferramenta gráfica de gestão das informações da planta, conforme ilustrado na figura 5.

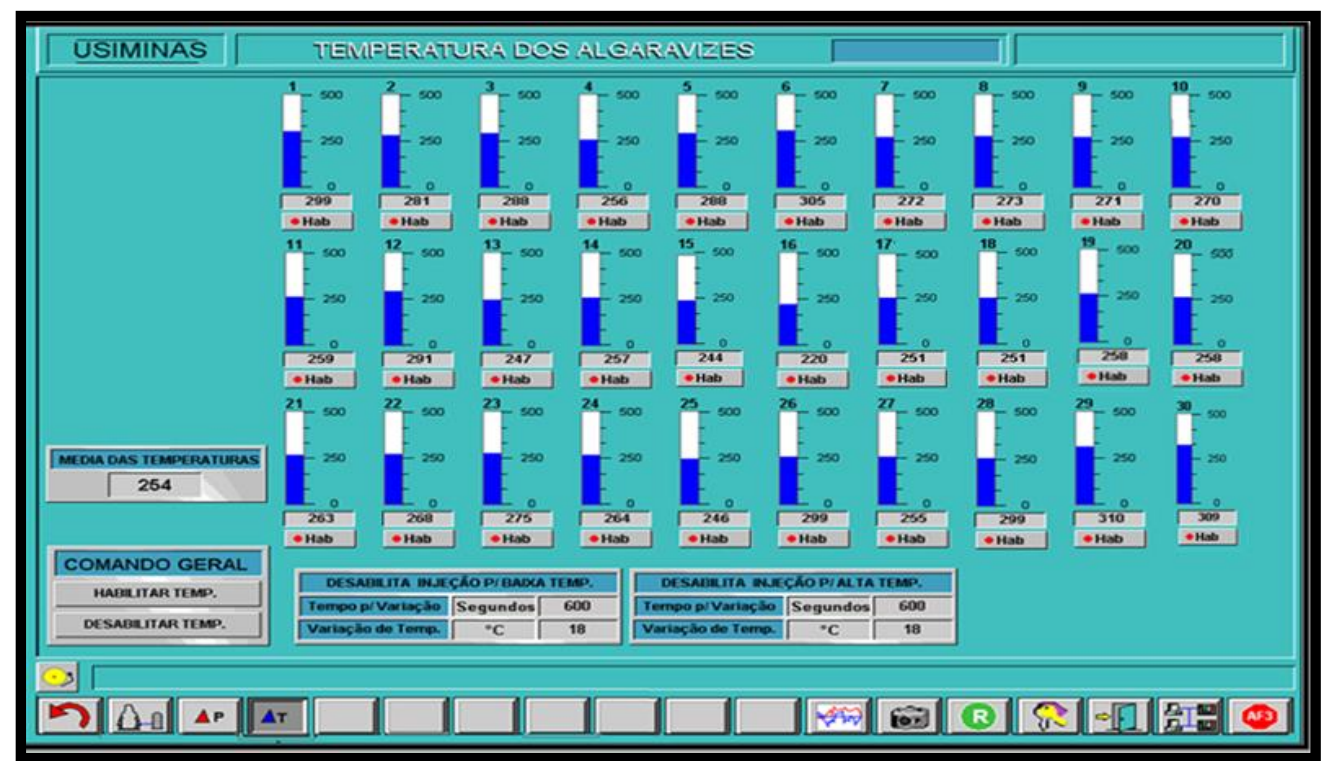

Figura 5. Tela da estação de supervisório do sistema de diferencial de temperatura.

\section{RESULTADOS E DISCUSSÃO}

A seguir é apresentado um registro de ocorrências no Alto-Forno 3 (evidência objetiva) no intuito de exemplificar o problema, indicando a necessidade e a eficácia dos sistemas implantados. Pela figura 6 é possível observar a indicação gráfica da ocorrência registrada no colapso estrutural do conjunto de sopro 7 em 23/04/2013. Ressalta-se que, nesta data os sistemas, embora instalados, ainda não estavam testados e implantados.

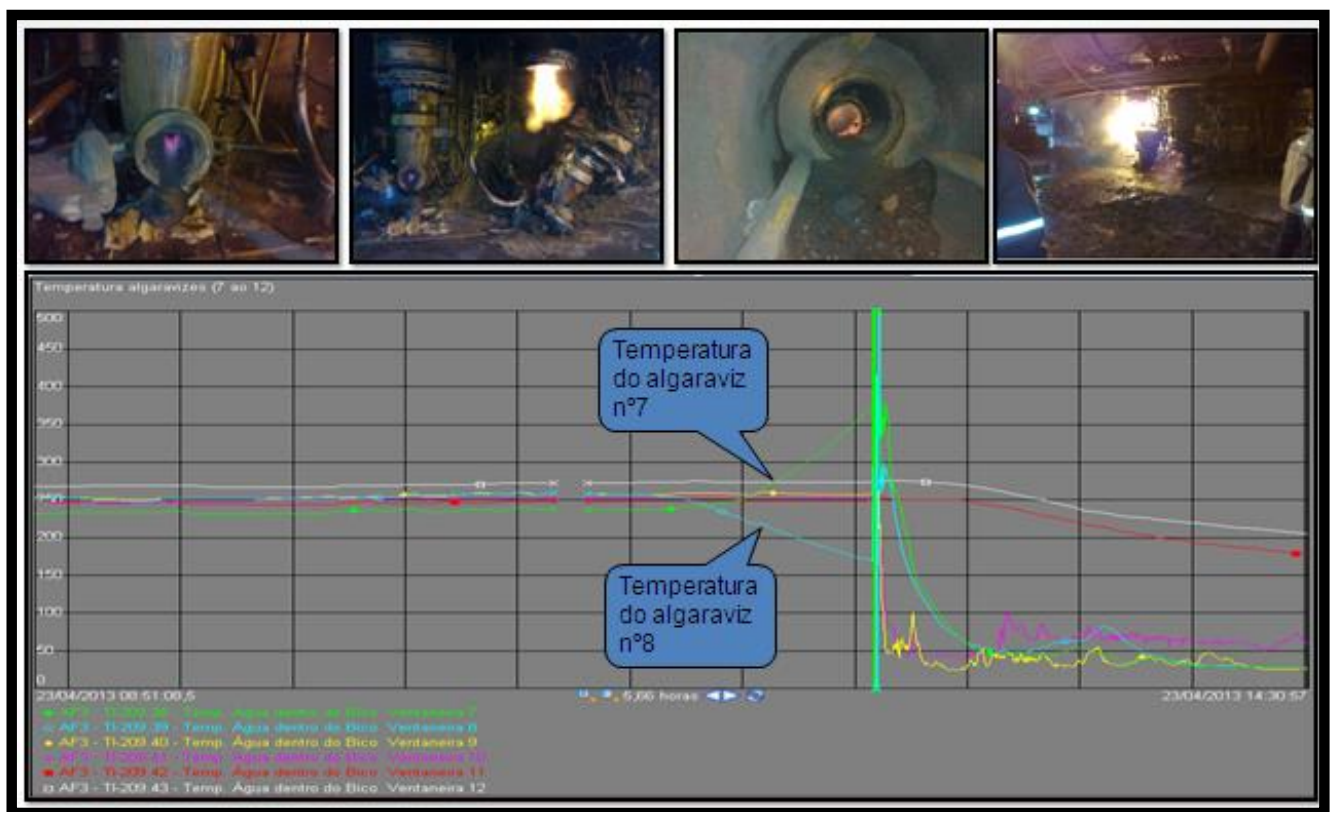

Figura 6. Esquema ilustrativo demonstrando o colapso do conjunto de sopro 7.

* Contribuição técnica ao 44 Seminário de Redução de Minério de Ferro e Matérias-primas, 15ㅇ Simpósio Brasileiro de Minério de Ferro e 2o Simpósio Brasileiro de Aglomeração de Minério de Ferro, 15 a 18 de setembro de 2014, Belo Horizonte, MG, Brasil. 
Com o perfeito funcionamento dos sistemas mencionados, conseguiu-se sanar as causas de acidentes ou princípio destes e melhorar a segurança operacional do Alto-Forno 3 no que diz respeito a acidentes causados pelo fenômeno explicado.

É importante ressaltar que não foi registrado nenhuma ocorrência desta natureza nos algaravizes do Alto-Forno 3 após implantação dos sistemas acima citados.

A equipe operacional do Alto-Forno 3, ainda está em processo de aprendizado e domínio das ferramentas citadas nesta contribuição técnica. Além disso, está em andamento um projeto complementar que visa a instalação das câmeras de vídeo para monitoramento individual por conjunto de sopro. Assim, com o monitoramento online de pressão, temperatura e visual por ventaneira, os ganhos em segurança operacional e, consequentemente, melhores ganhos em desempenho serão plenamente alcançados na operação do alto-forno.

\section{CONCLUSÃo}

Com os sistemas de controles pelo diferencial de pressão e temperatura devidamente instalados e ajustados, todas as expectativas operacionais foram confirmadas, com destaque para: (i) melhor segurança de pessoas; (ii) maior confiabilidade do sistema; (iii) monitoramento operacional online; e, (iv) maior estabilidade operacional.

\section{Agradecimentos}

Aos colaboradores das gerencias envolvidas da Usiminas Usina de Ipatinga, e a todos que de alguma forma dedicaram e contribuíram para o sucesso desse trabalho.

\section{REFERÊNCIAS}

1 Fernandes MV, Duarte WA, Carvalho JS. Terceira Campanha do Alto-Forno 3 da Usiminas In: $31^{\circ}$ Seminário de Redução de Minério de Ferro-Abm, Santos: ABM, 2000. 10p.

2 Babich AS, et all. - Co-Injection Of Noncoking Coal And Natural Gas In Blast Furnace. Isij International, 1999; 39(3): 229-238.

* Contribuição técnica ao 44 Seminário de Redução de Minério de Ferro e Matérias-primas, 15오 Simpósio Brasileiro de Minério de Ferro e 2ํ Simpósio Brasileiro de Aglomeração de Minério de Ferro, 15 a 18 de setembro de 2014, Belo Horizonte, MG, Brasil. 